\title{
The Scholar Looks at the Library
}

IN THE course of reading about Andrew 1 Carnegie the other day, I came across a remark he made that, if he had his life to live over again, he would want to be a librarian. I am tempted to ask this distinguished group for those who, if they had their lives to lead over again, would want to be Andrew Carnegie! The question is designed to show you that I have a great deal of sympathy for librarians.

I know from friends who are librarians something of the trials and hidden difficulties of the art-the great variety of demands made upon you and the inadequacy (as always) of budgets and assistance. So that it is with a kind of divided mind that $I$, as an outsider, come before you to make suggestions concerning the library. I should like you to remember that when I say "outsider," I don't mean a person who stays outside the library. On the contrary, as you know, the scholar wants nothing better from life than to be allowed to be totally surrounded by books. But the very title of the subject assigned to me, "The Scholar Looks at the Library," suggests a kind of "outsideness" which perhaps can be best described by saying that the scholar is outside the system which makes the library work.

Now this means that in everything I am going to say you will have to reinterpret my impression in the light of your inside knowledge. You may say, "Yes, he has observed something; perhaps he describes it inaccurately here or there, but there is something for us to thrash out together."

1 Paper presented at the Thirty-second Conference of Eastern College Librarians, Nov. 24, 1945.
I want to make my remarks very brief because I think that discussion brings out wisdom much more than talk from a single source. What I wish to say will fit under two general headings, equally important, it seems to me, though the first consists of trifles-trifles which add up to a good deal ; and the second is more obviously important. The two heads are Attention and General Knowledge.

Since the librarian is a person who technically or theoretically is behind the desk, it is perfectly clear that the relations between him or her and the public are comparable to those, let us say, of a bureaucrat, or of a person in a shop who has at hand certain desirable goods, meets a more or less anonymous public, and has to distribute those goods to that public. To do so requires a system, and the system is never so firmly registered in the mind of the public as it is in the mind of the librarian. Consequently, there occur all the possible frictions and misunderstandings which we are familiar with in the other forms of our life that fit the same pattern. But there is a difference, of course, in the library, for the librarian is a person trained to be as competent in dealing with the goods in his or her keeping as the public is in consuming them. That is why it seems to me the very first virtue of the librarian should be that of attentiveness.

Attentiveness is a widely ramified thing. I think if we listen to any casual conversation among friends, we can almost at once distinguish between the people who attend and the people who are merely there, inter- 
jecting random remarks out of their deep unconscious. And it strikes me that the librarian must not belong to the second category. The librarian must attend. Perhaps what I have in mind will be a little clearer if I give you some examples-examples which I shall try to wrap up in the feeling, in the impression that I frequently have when I go to a strange library where I don't know the officials or when I see, in the several libraries that I know, a person on whose attention I cannot count.

To begin with the scholar. $\mathrm{He}$ is in a kind of purposeful daze. The world would call him "absent-minded," but, as William James pointed out, that is only because he is "present-minded" somewhere else. Consequently when he strikes a snag, he wants a kind of instant response which will clear it up and enable him to go on with what he is thinking about. It is at this point that the librarian comes in, either to make the transition just as smooth as a train going over a switch on a good road, or just as awkward and deplorable as a derailment. The scholar is working from inside his own idea and he wants something immediately. If he is at all considerate, he words his question so it can be understood. On his part, the librarian ought to have that kind of tact and intuition and quickness, either to wait to find out what he wants in full, or to give him the feeling that if the book or fact can't be got at once, it can be reached fairly soon.

Some time ago while I was working with letters dating back to the nineteenth century which were dated sometimes only by the month and date, sometimes with a numeral and day of the week, I wanted a perpetual calendar. I went up to the librarian and said, "Can you tell me where I can find a perpetual calendar?"

The telephone rang at that moment and as she went to pick it up she said, "Calendar? Right over my desk."
Now that is irritating. I had to listen to her conversation over the telephone, and then when she came back I asked her again for what I wanted. She had never heard of a perpetual calendar; I might have been asking for a perpetual motion machine for all she knew. When I explained what it was, she said she was quite sure that there was nothing in the library that contained such an item. I found out subsequently from another librarian-which shows that there are differences among them-that the $W$ orld Almanac has a page which contains a perpetual calendar, to which I could have been directed.

To be sure, this kind of ignorance is not necessarily fatal, but the handling of it by the librarian was really a professional fault. On another occasion I wanted something even more special which apparently does not exist. I wondered whether the British periodicals of the nineteenth century had ever been listed with the names of their successive editors. That sentence as I have said it takes a certain amount of time to utter. Before I got to the end of it, the attendant to whom I put my question broke in, "British periodicals, nineteenth century?"- and gave me the title of a book in which there was a list of those periodicals.

I thought to myself after that experience that the very next inquiry that I put would have to be worded something like this:

"Miss-or Sir-I'm going to ask you a question. It is made up of three parts. ..."

But I needn't go on. You see what I had in mind-to calm down the impulsiveness and repress to a certain extent the knowledge which was bubbling up there much too soon.

There is a third type of inattention, of nervousness, of incompetence, or what you will, which strikes me as connected with the difficulties of the profession. And remember that I know that the successive persons who 
come up to the desk ask for all sorts of things ranging from astronomy to the comics and that it is unreasonable to expect that everyone will be equally prepared to answer all those questions. I am not talking about the ability to give the answer but about the form in which it is couched and the degree of fellow feeling with the person who is asking the question.

This third fault is the worried look, the frown, the air of suspecting that either this next question is going to be perfectly insane or, the opposite, too profound. It is often an excessive modesty which paralyzes the librarian and makes him feel, "I can never meet that requirement because I am not up to it."

In pointing out these trifles-and I know that they are trifles in any single instance, though they do add up to a whole atmosphere-I am not suggesting that librarians should put on any kind of smooth manner or anything resembling the Jehovah complex of the nurse in the doctor's office who makes you feel that everything is all right when you are dying by inches. That would be too bad. I don't think there is one manner for all persons, but I think that every person who is behind a desk has a certain duty. I have had a little desk experience myself, so I know how irritating it can be to supply endless answers and how stupid people seem when one is on the receiving end. But one has an obligation, it seems to me, of putting one's knowledge at the disposal of the inquirer in a calm, collected, sympathetic manner, without affectation and without suggesting that the particular crisis is a crisis. Because it isn't a crisis; because, theoretically, anything can be found or answered; and, if something cannot be found, it is just as easy to state this fact in a manner that leaves no scar from the encounter.

So much for attentiveness which, let me repeat, is something that has to be culti- vated. It doesn't come by itself. You have to be a kind of antenna receptive to all sorts of vibrations - the vibrations of personality, of intellectual quality and kind; it is almost a psychiatric job, particularly in modern times when neuroses are equal in number to the total of the population.

Between attentiveness, which is the application of a system to a demand, and the second head under which I want to make a few remarks, that of General Knowledge, the bridge is the technique of librarianship. I mean the Dewey Decimal System, the stack numbers, and all the paraphernalia, classifications, and cards. It seems to me that, important as those things are, they are like the technique of any art-they should be concealed for the art to be successful. I know that here I am in opposition to some of the members of my own craft who think that scholarship, to be good, must be displayed. I think it should be hidden, and I think it should be hidden because it is the scaffolding, and not the edifice.

At any rate, I should think that it would be worth considering whether librarians ought not to conceal as much as possible their knowledge of the system. If, for example, I ask for a certain kind of book in the reference room, I think it would be better not to hear the wheels going around by which the librarian arrives at the correct answer. I confess that as a reader of books I am somewhat annoyed when I hear a librarian half audibly mention the class number of a work I happen to mention. The system should be hidden, and one good way to achieve this is to have it absolutely clear in the minds of everybody, so clear that it can be forgotten like all the automatic things we do. Why, for example, is there not in every library a chart posted, indicating to the stranger how he can find his way around the library without asking any questions? Remember that the reader and scholar is 
bent upon something else than "using the library." He is bent on reading a book, which is rather a different thing. When we are bent on eating, we are not at the festal board to manipulate knives and forks. They are instruments, and they are more instrumental when we don't even know that we are using them at all. Similarly with library technique, the link between attentiveness, which is a human quality, and the intellectual substance that forms my second heading: General Knowledge.

On this second point, let me say at the outset that the ideal would be to have no distinctions whatever between librarians and scholars: scholars should be librarians and librarians should be scholars. They should be merely emphasizing one or the other side of a single operation, i.e., the using of books. And books are the repository of knowledge. General knowledge, by its very nature, cannot be given precise limits. You cannot make a list of what a person should know; but I confess that I have been struck again and again, and rather sadly impressed, by the want of general knowledge among librarians. I am aware of how much they would have to know in order to make every person who comes to the library feel that it was in charge of a person exactly as well informed as the user. Besides, we may all have exaggerated notions of how much we know. Yet it seems to me that there are certain things-certain kinds of knowledge and, in the absence of knowledge, kinds of apprehending, of enlightened guessworkwhich come from handling books and reading them. Let me illustrate.

Some time ago I was at a small college for a few days giving a short series of lectures, and I made a habit of going to the library and doing some reading and notetaking. The librarian seemed to me a very charming and well-informed woman who, on the third or fourth day, greeted me by saying, "What can we do for you this morning?"

I said, "Well, you can, if you want, save my looking something up in the catalog. Do you happen to have Tooke's Diversions of Purley?"

Her reply was: "We have very little on games."

I had to say, "It's not a book about games, it's a book about words and grammar."

She said, "Who is the author?"

"John Horne Tooke. It may be filed under Horne or Tooke." -

To which she said, "Oh, it would be Tooke here."

She didn't know what the Diversions of Purley were; she didn't know that John Horne was his real name and Tooke an adopted name and that, in some older collections, the original name is listed. There is no great crime in not knowing these facts; but when you pile up omissions of that character-when you ask for the Greek Anthology, and you are asked, "Who made the collection?"; when the Anatomy of Melancholy is thought to be a medical book -you begin to have an uncomfortable sense that the person is not well-read or welleducated. And such persons, wherever they may have their place in our vast and democratic universe, do not, as I see it, belong in libraries. Libraries are not just a great system, but collections of books. They have, or should have, an atmosphere of learning. I am quite sure that those of you who have studied in the Paris Bibliothèque Nationale have been offended, as I have been inwardly offended, by the fact that the attendants who deliver the books are absolutely illiterate, ill-bred, rude, and incompetent persons. There is something wrong with the atmosphere they create, quite apart from the bald question of inefficiency and of constant mistakes and confusion. In France, of course, it is a political 
difficulty, and here it is some other kind of difficulty, which I shan't characterize because I am sure you know more about it than I do. It may be that the training in the system is too arduous or too long; it may be that libraries haven't staffs large enough. If that is so, it seems to me that it behooves the profession as a whole to make this representation to the authorities and provide opportunities for librarians to read, to become well-informed, and to serve their .public in that intangible, yet important, way of being the same kind of person.

I should like librarians even to share the prejudices of scholars-and I shall give you some few instances of what I mean.

Some months ago I read Fremont Rider's book about microcards, which struck me as very interesting, beautifully thought out, and very well written. I was shocked, however, by two things-one large and one small. The large thing was the author's reinforcing the views of someone whom he quotes to the effect that, for the research scholar, secondary materials and writings of small merit are very important. That is, a man who is doing research in cultural history wants to know what all sorts of unimportant scribblers said about Keats or Shelley, and he also wants to know what critics and writers of textbooks may have said on his subject, narrow or wide. The fact that this truth had to be pointed out to the library profession came to me as a shock. Apparently, librarians formerly thought that only original materials-only the $\mathrm{Ca}$ pitularies of Charlemagne-could possibly come under the heads of research materials. This argues an ignorance not of fact, but an ignorance of perception, which I think a lamentable sign of the cleavage between scholar and librarian.

The trifling thing I want to add is probably one that you will give me no mercy about. I noticed throughout Mr. Rider's book, and I have since noticed in other publications relating to libraries, that the word "catalogue" is spelled "catalog." That's fine; "programme" with one $m$; "dialogue" ending in $g$; but then when I get to the combined forms and get "cataloging," I balk! I want to pronounce it "cat-alodging, cat-a-lodger." And I think that is a prejudice shared by almost every one who has been brought up in a certain tradition.

Maybe I am reading too much into this. Yet the kind of prejudice I refer to is of some importance; generalize it to other things, to more indescribable attitudes, and you will see that in your own lives you would, I think, be happier if you could approximate to the attitude of those whom you serve. Note, in passing, this word "serve:" from prejudice, again, I should like to leave it in its verbal form. On the same grounds as I object to "cataloging," so I object to "library service." The phrase reminds me unpleasantly of service stations for gasoline and oil. These are books that we are dealing with, and I want, not library service, but librarianship-a fit parallel to musicianship. You do not say, "The Budapest Quartette gives excellent musical service."

In short, I am talking about tone, and tone is always related to trifles. Trifles, moreover, always have two aspects-the way which technique or system or a certain kind of indifference to ultimate consequences directs; and the other way, the way that comes from reflection, from meditation, from readingfrom all the things which, if we shared them in common, would make my existence here entirely unnecessary. The scholars and the librarians would then be one group of people, at harmony with one another-insofar as there is harmony in human groups-and only at each other's throats for the good reasons, of which you are now going to inform me. 